\title{
MYCOFLORA STUDY IN A WHEAT FLOUR MILL OF ARGENTINA
}

\author{
Aringoli, E.E.*; Cambiagno, D.E.; Chiericatti, C.A.; Basilico, J.C.; M.L.Z. Basilico
}

Cátedra de Microbiología, Facultad de Ingeniería Química, Universidad Nacional del Litoral, Santiago del Estero 2829 (3000) Santa Fe, Argentina.

\begin{abstract}
The mycoflora of the environment: wheat conditioning, milling and screening, and filling zone, as well as, raw material -wheat-, intermediate product -grits- and end product -flour- on day 1, and after cleaning improvements -days 45 and 90- were studied in an Argentine wheat mill. Samples were incubated at $28^{\circ} \mathrm{C}$ for 5-7 days on Malt Extract Agar with chloramphenicol (100 $\left.\mathrm{mg} \mathrm{L}^{-1}\right)$ and the results were expressed in colony forming units per cubic meter of air $\left(\mathrm{CFU} \mathrm{m} \mathrm{m}^{-3}\right)$ or per gram of sample $\left(\mathrm{CFU}^{-1}\right)$, respectively. Fungal genera and species were isolated and identified and the potential toxicogenic capacity of the Aspergillus flavus and Fusarium graminearum isolated was studied. Time-Place and Time-Product multifactorial ANOVA were carried out. After cleaning improvements, CFU m ${ }^{-3}$ of air decreased as a function of time. Cladosporium and Alternaria were abundant in every zone, Aspergillus predominated in the wheat conditioning zone and Penicillium and Eurotium decreased with time. Wheat was more contaminated than grits and flour; Aspergillus, Eurotium and Mucoraceae family were the most abundant. Deoxynivalenol was above the levels allowed in wheat, being acceptable in grits and flour. Aflatoxin and Zearalenone showed acceptable levels. When studied in vitro, 53\% of Aspergillus flavus and 100\% of Fusarium graminearum isolates, produced Total Aflatoxins, and Deoxynivalenol and Zearalenone, respectively.
\end{abstract}

Key words: mycoflora, environment, wheat mill.

\section{INTRODUCTION}

In 2009, wheat production in Argentina was 13 million tonnes, 5 million tonnes of flour being produced in the 146 mills found in the country. (28).

During the process in the flour mills, bioaerosols are formed from particles of biological origin or with biological activity which can affect human beings because of processes of infectivity, allergenicity, toxicity or others (22). Bioaerosols include molds and their toxic metabolites, air being an excellent vehicle for their dispersion $(2,12)$.

The Food and Agriculture Organization (18) reported that approximately $25 \%$ of the cereal-based foods produced in the world are contaminated with mycotoxins, which are secondary metabolites produced by filamentous molds causing diseases in vertebrates when ingested, inhaled or skin absorbed (19). 
Molds, on the other hand, are associated with human allergic diseases resulting from the exposition to spores, vegetative cells or metabolites characteristic of these microorganisms (17, 23, 27).

The basic and unquestionable aspects that an agro-food industry producing innocuous foods should achieve are those of the hygiene-sanitation of the production environment and the raw material. Therefore, the evaluation of the environmental fungal contamination is an important starting point in those cereal industrialization plants, in order to ensure healthy working conditions and the quality of raw material ( 3 , 14, 30, 37, 39). Although several wheat studies have been carried out during harvests in Argentina (6, 13, 15, 21, 33, 34), scarce studies have been reported concerning the milling process (31).

The aim of this work was to determine fungal contamination in the environment air and in the raw material, as well as that resulting from the flour production in a wheat mill, as a function of the cleaning improvements carried out and wheat quality; the focus being on molds, since they represent the highest toxicological risk.

\section{MATERIALS AND METHODS}

\section{Sampling plan}

Sampling was carried out in summer, in an Argentine wheat flour mill located at the heart of the central plain -pampa húmeda-, the wheat-producing region of the country. The mill, with the latest technology equipment which produces milling products with appropriate moisture contents, has a storage capacity of 37000 tonnes and a flour production capacity of 150 tonnes day ${ }^{-1}$.

On day 1, air sampling was carried out in cuadruplicate in three of the zones considered more contaminated: Wheat Conditioning -WC-, Milling and Screening -MS- and flour Filling Zone -FZ-. Based on the results obtained in this case, cleaning system improvements were implemented, repeating the sampling at 45 and 90 days. Solid samples were also taken at the entrance of the Wheat Conditioning zone -wheat-, the Milling and Screening zone -grits- and the Filling Zone -flour-. During sampling, the environmental conditions of temperature $-{ }^{\circ} \mathrm{C}$ - and relative humidity $-\mathrm{RH} \%$ - were recorded with a psychrometer, using the wet bulb method.

\section{Air sampling}

An equipment -Standard RCS sampler -Biotest Diagnostic Corp., Denville, N.J., USA- based on the sampling of a known volume of air impacting on multiwell plates was used in this case. Malt Extract Agar -MEA- with the addition of chloramphenicol $\left(0.1 \mathrm{~g} \mathrm{~L}^{-1}\right)$ was used to prevent the bacterial growth, and dichloran $0.2 \%(\mathrm{w} / \mathrm{v})$ to inhibit rapid-growth molds $(5,35,41,43)$. Then, the multiwell plates were carried to the laboratory and incubated for 3-5 days at $27^{\circ} \mathrm{C}$ (32). The equipment was cleaned with isopropylic acid before each sampling (5).

\section{Solid sampling}

Samples of about $1 \mathrm{~kg}$ of wheat -W-, grits -G- and flour F- ready to be filled were taken from zones WC, MS and FZ, respectively, and put in sterile bags. Once in the laboratory, they were subsampled under sterile conditions, the final $100 \mathrm{~g}$ of samples being ground in a cutting mill. An aliquot $-10 \mathrm{~g}-$ taken from each sample was homogenized with $90 \mathrm{~mL}$ of 0.1 $\%(\mathrm{w} / \mathrm{v})$ peptone water. Serial dilutions were made up to the $10^{-5}$ dilution, in tubes containing $9 \mathrm{~mL}$ of the same diluent. After that, $1 \mathrm{~g}$ of each sample and $1 \mathrm{~mL}$ of each dilution was plated onto Petri dishes containing MEA, with the addition of chloramphenicol and dichloran $(6,10)$. This step was carried out in duplicate. At last the plates were incubated at $27^{\circ} \mathrm{C}$ for 5 days for their subsequent analysis (32).

\section{Count, isolation and identification of the fungal flora}

The count of the colonies grown on the multiwell plates was performed and the results were expressed as colony

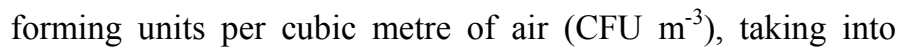
account factors such as sampling time and equipment factor. 
Solid samples counts were expressed as colony forming units per gram $\left(\mathrm{CFU} \mathrm{g}^{-1}\right)$.

Colonies grown were subjected to a previous macroscopic and microscopic observation so as to determine the distinctive characteristics of each genus. They were then recultivated in MEA until pure colonies were obtained, which were then cultivated in different media and culture conditions for the identification of species $(10,20,29,32,36)$. Non-sporulated colonies were streaked to plates with Spezieller Nährstoffarmer Agar-SNA- medium and incubated under the same conditions to allow for their sporulation (5).

\section{Mycotoxin determination in solid samples}

Total Aflatoxins, B and G groups -AF-, Deoxynivalenol DON- and Zearalenone -ZEA- were determined in solid samples using Enzyme-Linked ImmunoSorbent Assay ELISA-, recommended for analysis of cereals and derivatives RIDASCREEN ${ }^{\circledR}$ FAST - R-Biopharm AG, Darmstadt, Germany-. Concentrations were measured photometrically at $450 \mathrm{~nm}$ with a STAT Fax 321/PLUS reader -Awareness Tech., $\mathrm{Inc}^{\circledR}$, Palm city, USA.-. Quantification limits were $1.7 \mu \mathrm{g} \mathrm{kg}^{-1}$ for AF, $200 \mu \mathrm{g} \mathrm{kg}^{-1}$ for DON and $50 \mu \mathrm{g} \mathrm{kg}^{-1}$ for ZEA, (38).

\section{Aspergillus flavus and Fusarium graminearum toxicogenic capacity}

Isolates of $A$. flavus and $F$. graminearum were recultivated on Oat Agar -OA- and Potato Dextrose Agar PDA-, respectively (36) at $27{ }^{\circ} \mathrm{C}$ for $10-15$ days to determine their toxicogenic capacity according to the slightly modified (16) method. It consists in growing each strain under the above-mentioned culture conditions, punching out a $1 \mathrm{~cm}$ centre of the colony and placing it into a hemodialysis tube with $500 \mu \mathrm{l}$ of extractant solvent according to ELISA technique -RIDASCREEN ${ }^{\circledR}$ FAST - R-Biopharm AG, Darmstadt, Germany-. The production capacity of AF, DON and ZEA were then determined.

\section{Treatment of experimental data}

Fungal contamination expressed as $\mathrm{CFU} \mathrm{m} \mathrm{m}^{-3}$ and $\mathrm{CFU} \mathrm{\textrm {g } ^ { - 1 }}$ were transformed to decimal log to perform the Multifactorial ANOVA tests: Time -1, 45 and 90 days-, Zone -WC, MS and FZ- for the air samples; and Time -1, 45 and 90 days-, Samples $-\mathrm{W}, \mathrm{G}$ and F- for the solid samples (4). Abundance $-\mathrm{n}^{\mathrm{o}} \mathrm{CFU}$ Genus / $\mathrm{n}^{\mathrm{o}}$ Total CFU x 100) was determined in air and solid samples. Excel and Statgraphics Version 083.0 were used as informatic tools.

\section{RESULTS AND DISCUSSION}

Table 1 shows the values of environmental fungal count in the different zones -WC, MS and FZ- as a function of time -1, 45 and 90 days- and Table 2 the (Time-Zone) Multifactorial ANOVA values, which showed significant differences (pValue $<0.05$ ) in Time and Zone for the Total Count.

The significant differences found as a function of time show the improvements in the cleaning conditions adopted; being necessary to point out that solid residue on floor and machines could be observed during the first sampling. As regards the Zone, a higher production of fungal bioaerosols appeared on FZ for the days under study, originated in the flour screening process and the hopper discharge for subsequent fractionation and filling. Although no data on environmental pollution on wheat mills have so far been reported, the levels of counts here encountered would be in agreement with those found by Adhikari et al. (2) for environments of agricultural product storage. As for the genera identified, Cladosporium and Alternaria were the most abundant ones -Table 1-, no significant differences being shown for Time and Zone in the ANOVA study, which agrees with studies made in house environments in the region $(4,5)$. On the other hand, genus Aspergillus, was more abundant in WC, whereas Penicillium and Eurotium decrease in function of cleaning, like other authors state $(2,7)$. Cladosporium and Alternaria genus are considered allergenic, and some Alternaria species are potential mycotoxins producers. Epicoccum can also cause allergenic and antigenic cross-reactivity, thus enhancing those processes (8), and this genus was isolated mainly from the MS zone. The main species with those characteristics 
were Cladosporium cladosporioides, Alternaria alternata, fumigatus and 3\% to A. clavatus respectively; and isolates of Epicoccum nigrum; isolates of Aspergillus, of which 80\% Fusarium, of which 58\% corresponded to F. graminearum, corresponded to A. flavus, $12 \%$ to A. terreus, $5 \%$ to A. $30 \%$ to F. equiseti and $12 \%$ to F. oxysporum.

Table 1. Environmental fungal counts in CFU $\mathrm{m}^{-3}$ of air for Time (day 1, 45, 90) and Zone (WC: wheat conditioning, MS: milling and screening, FZ: filling zone).

\begin{tabular}{|c|c|c|c|c|c|c|c|c|c|}
\hline \multirow{3}{*}{$\underset{\text { (species)* }}{\text { Genus }}$} & \multicolumn{9}{|c|}{ Fungal Counts (CFU m $\left.^{-3}\right)$} \\
\hline & \multicolumn{3}{|c|}{ day 1} & \multicolumn{3}{|c|}{ day 45} & \multicolumn{3}{|c|}{ day 90} \\
\hline & WC & MS & FZ & WC & MS & FZ & WC & MS & $\mathbf{F Z}$ \\
\hline Totals & 9400 & 16400 & 24000 & 11000 & 8800 & 12200 & 5200 & 8400 & 10200 \\
\hline Cladosporium & 2200 & 5400 & 5800 & 3400 & 2000 & 2200 & 2600 & 1800 & 1800 \\
\hline Alternaria & 1400 & 3200 & 1600 & 3800 & 3800 & 2800 & 1000 & 3000 & 2600 \\
\hline Aspergillus* & 3000 & 200 & 2000 & 200 & ND & 3600 & ND & 800 & 3000 \\
\hline (A. candidus) & $\left(\mathrm{ND}^{\dagger}\right)$ & $(36)$ & (ND) & (128) & (ND) & $(120)$ & (ND) & $(12)$ & $(240)$ \\
\hline (A. clavatus) & (ND) & (ND) & (ND) & (ND) & (ND) & (ND) & (ND) & (ND) & (ND) \\
\hline (A. flavus) & $(3000)$ & $(164)$ & $(2000)$ & (ND) & (ND) & $(3240)$ & (ND) & $(788)$ & $(2760)$ \\
\hline (A. fumigatus) & (ND) & (ND) & (ND) & (ND) & (ND) & (ND) & (ND) & (ND) & (ND) \\
\hline (A. terreus) & (ND) & (ND) & (ND) & (ND) & (ND) & (180) & (ND) & (ND) & (ND) \\
\hline Penicillium & 1000 & 1800 & 8200 & 400 & ND & 1200 & 200 & ND & ND \\
\hline Eurotium & 1600 & 2400 & 400 & 2000 & 600 & 1600 & 400 & ND & ND \\
\hline Epicoccum & ND & 2000 & ND & 200 & 1400 & 400 & 400 & 2000 & 800 \\
\hline Fusarium & ND & ND & 800 & 600 & 600 & 200 & ND & ND & ND \\
\hline (F. equiseti) & (ND) & (ND) & (80) & (ND) & (ND) & (ND) & (ND) & (ND) & (ND) \\
\hline (F.graminearum) & (ND) & (ND) & (720) & (576) & $(600)$ & (200) & (ND) & (ND) & (ND) \\
\hline (F.oxysporum) & (ND) & (ND) & (ND) & (24) & (ND) & (ND) & (ND) & (ND) & (ND) \\
\hline Absidia & ND & ND & ND & ND & ND & ND & ND & ND & 48 \\
\hline Mucor & ND & ND & ND & ND & ND & ND & ND & ND & 12 \\
\hline Rhizopus & 200 & 400 & 400 & 400 & ND & ND & ND & ND & 1740 \\
\hline Yeasts** & ND & 200 & 3800 & ND & ND & ND & 600 & ND & ND \\
\hline Others $* * * *$ & ND & 800 & 1000 & ND & 400 & 200 & ND & 800 & 200 \\
\hline
\end{tabular}

*Potential toxicogenic species

** not genus were determined

***Genus: Stemphylium, Aureobasidium, Moniliella, Trichoderma and sterile mycelia

${ }^{\dagger} \mathrm{ND}$ : Non detected. Detection Limit: $12 \mathrm{CFU} \mathrm{\textrm {m } ^ { - 3 }}$

day 1: pre-cleaning system improvements, day 45 and day 90 : controls of cleaning system improvements

Table 2. Multifactorial ANOVA of environmental fungal genus for Time (day 1, 45, 90) and Zone (wheat conditioning, milling and screening, and filling zone)

\begin{tabular}{lccccc}
\hline & \multicolumn{2}{c}{ Multifactorial ANOVA } & & \multicolumn{2}{c}{ Zone } \\
\cline { 2 - 3 } \cline { 5 - 6 } \cline { 5 - 6 } \cline { 5 - 6 } Total $\log$ & \multicolumn{2}{c}{ Time } & & & \multicolumn{2}{c}{ F-Ratio } & p-Value* \\
\cline { 2 - 3 } $\log$ Cladosporium & 19.26 & 0.0000 & & 13,31 & 0,0000 \\
$\log$ Alternaria & 3.12 & 0.0580 & & 0.39 & 0.6788 \\
$\log$ Aspergillus & 2.53 & 0.0959 & & 2.95 & 0.0670 \\
$\log$ Penicillium & 0.43 & 0.6512 & & 10.11 & 0.0004 \\
$\log$ Eurotium & 21.17 & 0.0000 & & 2.84 & 0.0739 \\
$\log$ Epicoccum & 8.60 & 0.0110 & & 2.02 & 0.1494 \\
$\log$ Fusarium & 1.88 & 0.1700 & & 10.76 & 0.0003 \\
$\log$ Rhizopus & 3.44 & 0.0446 & & 0.19 & 0.8275 \\
$\log$ Yeasts** & 0.96 & 0.3939 & & 2.12 & 0.1373 \\
$\log$ Others*** & 4.42 & 0.0204 & & 2.06 & 0.1440 \\
* $^{*}<0$ 05 & 0.28 & 0.7591 & & 4.23 & 0.0237 \\
\hline
\end{tabular}

$* \mathrm{p}<0.05$

** not genus were determined.

***Genus: Stemphylium, Aureobasidium, Moniliella, Trichoderma, Absidia, Mucor and sterile mycelia. 
Table 3 shows total fungal counts for the products under study -W, IP and F- as a function of time -1, 45 and 90 days-. Fungal contamination can be seen to decrease with milling process progress, wheat showing the higher variability in contamination depending on the lots considered (6).

Table 3. Products (W: wheat, G: grits, F: flour) fungal counts in $\mathrm{CFU} \mathrm{g} \mathrm{g}^{-1}$ for Time (day 1, 45 and 90)

\begin{tabular}{|c|c|c|c|c|c|c|c|c|c|}
\hline \multirow{3}{*}{$\underset{\text { (species)* }}{\text { Genus }}$} & \multicolumn{9}{|c|}{ Fungal Counts (CFU g g } \\
\hline & \multicolumn{3}{|c|}{ day 1} & \multicolumn{3}{|c|}{ day 45} & \multicolumn{3}{|c|}{ day 90} \\
\hline & $\mathbf{W}$ & G & $\mathbf{F}$ & $\mathbf{W}$ & $\mathbf{G}$ & $\mathbf{F}$ & $\mathbf{W}$ & $\mathbf{G}$ & $\mathbf{F}$ \\
\hline Totals & 135 & 110 & 140 & 270 & 60 & 95 & 360 & 170 & 145 \\
\hline Cladosporium & $\mathrm{ND}^{\dagger}$ & ND & ND & 75 & ND & 20 & ND & 5 & ND \\
\hline Alternaria & ND & ND & ND & 40 & ND & 35 & ND & ND & ND \\
\hline Aspergillus & 15 & 65 & 105 & 25 & 35 & 5 & 15 & 90 & 105 \\
\hline (A.candidus) & $(15)$ & $(65)$ & $(105)$ & $(25)$ & $(30)$ & (ND) & (14) & $(89)$ & $(100)$ \\
\hline (A. clavatus) & (ND) & (ND) & (ND) & (ND) & (ND) & (ND) & (ND) & (ND) & (ND) \\
\hline (A. flavus) & (ND) & (ND) & (ND) & (ND) & (ND) & (ND) & (ND) & (ND) & (ND) \\
\hline (A sydowii) & (ND) & (ND) & (ND) & (ND) & (ND) & (ND) & (ND) & $(2)$ & (4) \\
\hline Penicillium & 5 & 5 & 15 & ND & 20 & 20 & ND & 5 & 25 \\
\hline Eurotium & 110 & 30 & 10 & 100 & 5 & ND & 20 & 55 & 15 \\
\hline Eрісоссит & ND & 5 & ND & 20 & ND & ND & ND & ND & ND \\
\hline Fusarium & ND & ND & ND & 10 & ND & ND & ND & ND & ND \\
\hline (F. graminearum) & (ND) & (ND) & (ND) & (9) & (ND) & (ND) & (ND) & (ND) & (ND) \\
\hline (F. oxysporum) & (ND) & (ND) & (ND) & (1) & (ND) & (ND) & (ND) & (ND) & (ND) \\
\hline Absidia & 1 & 2 & $\mathrm{ND}$ & ND & $\mathrm{ND}$ & ND & 20 & ND & ND \\
\hline Mucor & ND & ND & ND & ND & ND & ND & 5 & ND & ND \\
\hline Rhizopus & 4 & 2 & ND & ND & ND & ND & 300 & 15 & ND \\
\hline Eupenicillium & ND & ND & 10 & ND & ND & ND & ND & ND & ND \\
\hline Emericella & ND & ND & ND & ND & ND & 5 & ND & ND & ND \\
\hline $\mathrm{SM}^{* *}$ & ND & ND & ND & ND & ND & 10 & ND & ND & ND \\
\hline Yeasts*** & 60 & 20 & ND & 15 & 5 & ND & 15 & ND & ND \\
\hline
\end{tabular}

Values of Time-Product Multifactorial ANOVA were significant only for the $\log _{10}$ of total counts as a function of Products (F-Ratio, 4.04 and p-Value, 0.043); the highest counts being found for $\mathrm{W}$, in agreement with Berghofer et al. (7). After leaving the silos, the grain undergoes a process of control and cleaning which includes sieving before entering the $\mathrm{WC}$ zone, the same authors (7) demonstrated that the microbial load in the flour depended directly on the wheat microbial quality and that, as grain processing advances, the fungal contamination decreases in the final product -grits and flour-.

A low fungal contamination was found in all $\mathrm{W}$ samples studied, although Kozak et al. (25) showed that fungal counts below the detection limit, based on viable count methods, can be even high enough to cause breathing problems. Genera Aspergillus and Eurotium were present during the three days of study, while Mucoraceae family, which includes principally isolates of the genera Rhizopus, were the most abundant in W at day 90 .

Although wheat is a susceptible cereal to Fusarium species in Argentina among other countries (6, 13, 15, 21, $31,33,34)$ low counts were observed in the present study, probably due to the good climatic conditions of the year, in storage and production quality of the environment -average $\mathrm{RH}$ $62 \%$-. Unlike the environmental counts, genera Cladosporium and Alternaria showed low figures, this would confirm that both genera would constitute an ordinary environmental flora. 
Isolates of genera Aspergillus, 62\% corresponded to $A$. candidus, $23 \%$ to A. flavus, $8 \%$ to A. sydowi, $5 \%$ to $A$. fumigatus and $2 \%$ to A. clavatus. Genus Fusarium was only isolated from $\mathrm{W}$ in low count at day $45,-F$. graminearum $60 \%$ and F. oxysporum 30\%-. Both genera and species identified are in agreement with data reported by other authors $(6,7,32,36)$ as regards abundance in cereals. Likewise, the same authors' report that most genera and species identified can grow with a relatively low water activity.

Fusarium species can produce plenty of bioactive metabolites, group B trichotecenes among them $(1,24)$, being DON the main wheat contaminant in Argentina (6, 13, 15, 21, 33,). DON occurrence is related with the presence of $F$. graminearum, also a good producer of another type of toxins of ZEA family. When analyzing the toxicogenic capacity of the $A$. flavus isolates, $53 \%$ were found capable of producing total aflatoxins, whereas $100 \%$ of the $F$. graminearum isolates turned out to be DON and ZEA producers under the working conditions.

Table 4 shows the values of mycotoxins considered in the solid samples. Despite A. flavus isolate, AF levels in wheat were lower than the quantification level, similar results being found for ZEA. Neither toxin was detected in the other products studied, which is in agreement with Berghofer et al. (7), probably because during milling the outer layer of wheat is removed, thus dragging the fungal load and decreasing the possible levels of mycotoxins to be detected in the end product (26). Aflatoxins contamination was shown to be of higher importance in other cereals and oilseeds than in wheat (40).

DON levels, conversely, overcame the maximum limits recommended for wheat $-1250 \mu \mathrm{g} \mathrm{kg}^{-1}$ - and, although the levels decreased in $\mathrm{G}$ and $\mathrm{F}$, figures close to those allowed were detected in flour $-750 \mu \mathrm{g} \mathrm{kg}^{-1}$ - (11). Although the presence of these mycotoxins has been studied in different foods, little is known regarding the occupational exposure to them and the effects on the workers' health $(14,42)$.

Table 4. Aflatoxins (AF), Deoxynivalenol (DON) and Zearalenone (ZEA) by immunoenzimatic methods (ELISA) in products (W: wheat, G: grits, F: flour)

\begin{tabular}{|c|c|c|c|c|c|c|c|c|c|}
\hline \multirow{3}{*}{ Time } & \multicolumn{9}{|c|}{ Mycotoxin Determination $\left.(\mu \mathrm{g} \mathrm{kg})^{-1}\right)^{(a)}$} \\
\hline & \multicolumn{3}{|c|}{$\mathbf{W}$} & \multicolumn{3}{|c|}{$\mathbf{G}$} & \multicolumn{3}{|c|}{$\mathbf{F}$} \\
\hline & $\mathbf{A F}$ & DON & ZEA & $\mathbf{A F}$ & DON & ZEA & $\mathbf{A F}$ & DON & ZEA \\
\hline day 1 & $\mathrm{ND}^{(1)}$ & ND & $\mathrm{ND}$ & ND & 100 & ND & ND & ND & ND \\
\hline day 45 & ND & 3600 & ND & ND & 800 & ND & ND & 700 & ND \\
\hline day 90 & 1.7 & 1800 & ND & ND & 700 & ND & ND & 700 & ND \\
\hline
\end{tabular}

${ }^{(1)}$ ND: Non Detected

(a) Quantification limits for total aflatoxins, deoxynivalenol and zeoralenone were $1.7 \mu \mathrm{g} \mathrm{kg}^{-1}, 2001.7 \mu \mathrm{g} \mathrm{kg}^{-1}$ and $501.7 \mu \mathrm{g} \mathrm{kg}^{-1}$ respectively.

A decrease in the fungal load was observed after cleaning conditions in the mill were improved as suggested, both in the environment and in the machinery used, as was shown in bakeries (9). Grain quality is important not only for the workers at their worksite but for the end product to be obtained. There exists an environmental flora, intrinsic to the mill itself, as well as another depending on the fungal load, which comes from the raw material being processed. Many allergenic and toxicogenic molds were detected, both in the environment and in the solid products. DON values in wheat decreased throughout the processing line, attaining allowed levels in the ready-to-use flour. However, cleaning conditions should be kept and controls in the wheat entering the plant and the mill environment should be done in order to adopt measures that ensure healthy conditions for the plant workers and high quality in the end product.

\section{ACKNOWLEDGEMENTS}

The authors acknowledge the financial support of the 
Universidad Nacional del Litoral, Santa Fe, Argentina, CAI+D 2009-2012. PI 15-92.

\section{REFERENCES}

1. Abramson, D.; Clear, R.M.; Gaba, D.; Smith, D.M.; Patrick, S.K.; Saydak, D. (2001). Trichothecene and moniliformin production by Fusarium species from western Canadian wheat. J. Food Prot. 64, 12201225.

2. Adhikari, A.; Reponen, T.; Lee, S-A.; Grinshpun, S.A. (2004). Assessment of human exposure to airborne fungi in agricultural confinements: personal inhalable sampling versus satationary sampling. Ann. Agric. Environ. Med. 11, 269-277.

3. American Conference of Governmental Industrial Hygienists. (1990). Documentation on flour dust. Cincinnati.

4. Aringoli, E.E.; Basilico, M.L.Z.; Althaus, R.; Basilico, J.C. (2008). Multivariate analysis of fungal association in the indoor air of Argentinean houses. Int. Biodeterior. Biodegrad. 62, 281-286.

5. Basilico, M.L.Z.; Chiericatti, C.; Aringoli, E.E.; Althaus, R.; Basilico, J.C. (2007). Influence of environmental factors on airborne fungi in houses of Santa Fe city, Argentina. Sci. Total Environ. 376, 143-150.

6. Basilico, M.L.Z.; Pose, G., Ludemann, V.; Fernéndez Pinto V.E.; Aríngoli E.E.; Ritieni, A.; Basilico, J.C. (2010). Fungal diversity and natural occurrence of fusaproliferin, beauvericin, deoxinivalenol and nivalenol in wheat cultivated in Santa Fe Province, Argentina. Mycotox. Res. 26, 85-91.

7. Berghofer, L.; Hocking, A.D.; Miskelly, D.; Jansson, E. (2003). Microbiology of wheat and flour milling in Australia. Int. J. Food Microbiol. 85, 137-149.

8. Bisht, V.; Singh, B.; Arora, N.; Gaur, S.N.; Sridhara, S. (2002). Antigenic and allergenic cross-reactivity of Epicoccum nigrum with other fungi. Ann. Allergy, Asthma, Immunol. 89, 285-291.

9. Bonetto, S. (2010). Evaluación y control de bioaerosoles fúngicos en la industria panadera/confitera. Thesis for Master of Environmental Engineering. National Technology University, Argentina.

10. Carmichael, JW.; Bryce Kendrick, W.; Conners, I.L.; Sigler, L. (1980), Genera of Hyphomycetes. University of Alberta Press. Canada.

11. Comunidad Europea. (2006). Normativas $N^{\circ} 1881 / 2006$ y $N^{\circ} 401 / 2006$.

12. Crook, B.; Sherwood-Higham, J.L. (1997). Sampling and assay of bioaerosols in the work environment. J. Aerosol Sci. 28, 417-426.

13. Dalcero, A.; Torres, A.; Etcheverry, M.; Chulze, S.; Varsavsky, E. (1997). Occurrence of deoxinivalenol and Fusarium graminearum in Argentinean wheat. Food Addit. Contam. 14, 11-14..

14. Douwes, J.; Thorne, P.; Pearce, N.; Heederik, D. (2003). Bioaerosol health effects and exposure assessment: progress and prospects. Ann. Occup. Hyg. 47, 187-200.
15. Fernandez Pinto, V.E.; Terminiello, L.A.; Basilico, J.C.; Ritieni, A. (2008). Natural occurrence of nivalenol and mycotoxicogenic potential of Fusarium graminearum strains in wheat affected by head blight in Argentina. Braz. J. Microbiol. 39, 1-6.

16. Filtenborg, O.; Frisvad, J.C. (1980). A simple screening method for toxicogenic fungi in pure cultures. LWT-Food Sci. Technol. 13, 128-130.

17. Fogelmark, B.; Thorn, J.; Rylander, R. (2001). Inhalation of (1 $\rightarrow 3)-\beta-D-$ glucan causes airway eosinophilia. Mediators Inflammat. 10, 13-19.

18. Food and Agriculture Organization of the United Nations. (1995). Worldwide regulations for mycotoxins, Paper 64, Rome.

19. Frisvad, JC.; Thrane, U.; Samson, R.A. (2007). Mycotoxin producers. In: Dijksterhuis, J. and Samson, R.A. (eds). Food Mycology: A Multifaceted Approach to Fungi and Food. Taylor and Francis Group. CRC Press, p.135-159

20. Gams, W.; Domsch, K.H.; Anderson, T-H. (1980). Compendium of Soil Fungi. Academic Press.

21. González, H.H.L.; Pacin, A.; Resnik, S.L.; Martínez, E.J. (1996). Deoxynivalenol and contaminant mycoflora in freshly harvested Argentinean wheat in 1993. Mycopathologia. 135, 129-134.

22. Hirst, J.M. (1995). Bioaerosols: introduction, retrospect and prospect, In: Cox, C.S. and Wathes, C.M.(eds). Bioaerosols Handbook. Lewis Publishers. Boca Raton, Florida. p. 1-10.

23. Houba, R.; van Run, P.; Doekes, G.; Heederik, D.; Spithoven, J. (1997). Airborne $\alpha$-amylase allergens in bakeries. J. Allergy Clin. Immunol. 99, 286-292.

24. Jestoi, M.; Ritieni, A.; Rizzo, A. (2004). Analysis of the Fusarium mycotoxins fusaproliferin and trichothecenes in grains using gas chromatography-mass spectrometry. J. Agric. Food Chem. 52, 14641469.

25. Kozak, P.P.; Gallup, J.; Cummins, L.H.; Gillman, S.A. (1979). Factors of importance in determining the prevalence of indoor molds. Ann. Allergy. 45, 167-176.

26. Lugauskas, A.; Raila, A.; Railiene, M.; Raudoniene, V. (2006). Toxic micromycetes in grain raw material during its processing. Ann. Agric. Environ. Med. 13, 147-161.

27. Menezes, E.A.; Carvalho, P.G.; Trindade, E.C.P.M.; Sobrinho, G.M.; Cunha, F.A.; Morato-Castro, F.M. (2004). Airborne fungi causing respiratory allergy in patients from Fortaleza, Ceará, Brasil. J. Bras. Patol. Med. Lab. 40 (2), 79-84.

28. Ministerio de Economía. Presidencia de la Nación. Argentina. Secretaría de Agricultura, Ganadería, Pesca y Alimentos. Estimaciones y Estadísticas. 2009. http://www.sagpya.mecon.gov.ar. Accessed diciembre 2009.

29. Nelson, P.E.; Toussoun, T-A.; Marasas, W.F.O. (1983). Fusarium species. An illustrated manual for identification. Pensylvania State, University Press.

30. Olsen, J.H.; Dragsted, L.; Autrup, H. (1988). Cancer risk and 
occupational exposure to aflatoxins in Denmark. Br. J. Cancer. 58, 392396.

31. Pacin, A.M.; Resnik, S.L.; Neira, M.S.; Molto, G.; Martinez, E. (1997). Natural occurrence of deoxynivalenol in wheat, wheat flour and bakery products in Argentina. Food Addit. Contam. 14, 327-331.

32. Pitt, J.I.; Hocking, A.D. (2009). Fungi and food spoilage. SpringerVerlag. New York.

33. Quiroga, N.; Resnik, S.L.; Pacin, A.; Martínez, E.; Pagano, A.; Riccobene, I.; Neira, S. (1995). Natural occurrence of trichothecenes and zearalenone in Argentinean wheat. Food Control. 6, 201-204.

34. Rizzo, I.; Lori, G.; Vedoya, G.; Carranza, M.; Haidukowski, M.; Varsavsky, E.; Frade, H.; Chiale, C.; Alippi, H. (1997). Sanitary factors and mycotoxin contamination in the Argentinean wheat crop 1993-94. Mycotoxin Res. 13, 67-71.

35. Roda, C.; Barral, S.; Ravelomanantsoa, H.; Duséaux, M.; Tribout, M.; Le Moullec, Y.; Momas, I. (2011). Assessment of indoor environment in Paris child care centers. Environ. Research 111, 1010-1017.

36. Samson, R.A.; Hoekstra, E.S.; Frisvad, J.C.; Filtenborg, O. (1995). Introduction to food-borne fungi. The Nethernlands: Centraalbureau voor Schimmelcultures. Nethernlands.

37. Sandiford, C.P.; Tee, R.D.; Taylor, A.J. (1994). The role of cereal and fungal amylases in cereal flour hypersensitivity. Clin. Exp. Allergy. 24, 549-557.

38. Signorini, M.L.; Gaggiotti, M.; Molineri, A.; Chiericatti, C.A.; Basilico, M.L.Z.; Basilico, J.C.; Pisani, M. (2012). Exposure asseement of mycotoxins in cow's milk in Argentina. Food Chem. Toxicol. 50, 250257.

39. Sorenson, W.G. (1990). Mycotoxins as potencial occupational hazards. Dev. Ind. Microbiol. 31, 205-211.

40. Stoloff, L. (1977). Aflatoxins - an overview. In: Rodricks, J.V.; Hesseltine, C.W.; Mehlman M.A. (eds). Mycotoxins in human and animal health. Patothox Pub. Inc., Park Forest South, Illinois, USA. p.728.

41. Su, H-J.; Wu, P-Ch.; Chen H-L.; Lee, F-Ch.; Lin, L-L. (2001). Exposure assessment ofindoor allergens, endotoxin, and airborne fungi for homes in southern Taiwan. Environ. Res. 85, 135-144.

42. Sudakin, D. (2003). Trichothecenes in the environment: relevance to human health. Toxicol. Lett. 143, 97-107.

43. Wu, P-Ch.; Su, H-J. J.; Ho, H-M. (2000). A comparición of sampling media for environmental viable fungi collected in a hospital environment. Environ. Research 82, 253-257. 